\title{
Key Factors for Improved Adoption of Emerging Technologies in Organizations Fueled by Design Thinking

\author{
Nandakumar Kumar
}

\begin{abstract}
Emerging technologies like internet of things (IoT), block chain, cloud computing, machine learning, big data analytics etc., are creating a wave of excitement and anxiety in the business community. An independent research in 2016 projected that companies world-wide will spend \$3.5 Trillion on IT over the next two years (Gartner, 2016). It also predicted that companies would tend to increase their expenditure on software and services over hardware. Software spending was projected to be up 6 percent in 2016 and to grow another 7.2 percent in 2017 to a total of \$357 billion. A proper investigation and analysis is needed to understand the key factors impacting adoption if such technologies in large corporations for extracting maximum benefits out of such initiatives.However, this buzz has not only created the art of the possibility of incorporating emerging technologies but also a bigger problem of enterprise wide relevant adoption. One of the much sought out after techniques in fueling the adoption of emerging technologies in large private enterprises is design thinking. Design Thinking is essentially a problem-solving approach, crystalized in the field of design, which combines a holistic user-centered perspective with rational and analytical research with the goal of creating innovative solutions (Tim Brown, 2009).There are several factors that are crucial to be addressed during the design thinking phase that will significantly impact the successful adoption rate of emerging technologies in companies. This demands that we take a closer look at not only the factors impacting adoption but also the actual design thinking exercise itself that will have a say in the adoption of such technologies. Our exercise aimed at gauging and analyzing the key factors for improved adoption while utilizing the design thinking approach leads us to define our problem statement as follows: What are the key factors for improved adoption of emerging technologies in business functions while incorporating design thinking techniques as a catalyst in large private enterprises?
\end{abstract}

Keywords: Adoption of emerging technologies, Artificial intelligence and automation, design thinking, intrinsic motivation, technology innovation

\section{INTRODUCTION}

A recent survey and report by Harvard business review reveals that nearly $70 \%$ of all internal initiatives in an organization fail (Nitin Nohria and Michael Beer, 2000). However, the IT spend by companies especially on emerging technologies are increasing every year. There is a disparity between spend and success rates of such initiatives baselined

Revised Manuscript Received on August 13, 2020.

* Correspondence Author

Nandakumar Kumar*, Department of DBA in management studies, S P Jain School of Global Management, Sydney, Australia. E-mail: nandakumar.dm18dba018@spjain.org

(c) The Authors. Published by Blue Eyes Intelligence Engineering and Sciences Publication (BEIESP). This is an open access article under the CC BY-NC-ND license (http://creativecommons.org/licenses/by-nc-nd/4.0/) around emerging technologies. This demands that we examine closely several internal and external factors during design and implementation of such technology initiatives to understand the disparity and accordingly mitigate it especially by using design thinking techniques.

Why Now?

This leads us to the question - Why now? There is a lot of emerging technologies like IoT, block chain, AI and machine learning and cloud computing that is redefining the technology landscape of global corporations. It is predicted that corporations world-wide would increase their expenditure on such emerging software and services by up to \$357 Billion (Gartner, 2016). This research would like to understand such factors impacting adoption and profitability of technologies on time by using catalyst frameworks like design thinking.

Why Is It Needed?

Once the factors impacting adoption rate of emerging technologies while using design thinking methods as catalysts are identified, we can then examine those factors closely for anomalies. This research would then define steps and precautions that needs to be taken during the design thinking exercise to ensure the anomalies are addressed and ironed out. Success rates of newer technology adoptions are very important considering the amount of investments carried out by these corporations.

\section{RESEARCH PROBLEM TOPIC, AREA AND KEY STAKEHOLDERS}

The topic of our research delves into the factors impacting enterprise wide adoption of emerging technologies. This research will be undertaken in the context of corporations that adopt emerging technologies like IoT, Block chain, Machine learning and cloud computing in the digitized business processes across their enterprise while using design thinking as a catalyst during ideation and brain storming phase.

The key stakeholders involved are those decision makers, design thinking consultants and people whose jobs directly involve interacting with these emerging technologies.

Objective of Research A lot is talked about only the positive impact, investment in billions and the excitement around emerging technologies. I would like to research the key factors that need to be considered during design thinking approach to ensure maximum profitability, return on investment and adoption of such technologies. Since, there could be a number of positive and negative factors involved, our objective is to identify the primary factors that impact and contribute to technology adoption and profitability.

Published By:

Blue Eyes Intelligence Engineering \& Sciences Publication (C) Copyright: All rights reserved. 
This input is vital in understanding while designing an enterprise-wide design-thinking led program on emerging technologies deployment.

5-Steps Defining Research Problem and Question

To define this research problem further using five-step process:

- Who? (Decision makers, design thinking consultants, Employees affected)

- Where? (Working in processes to be transformed by emerging technologies)

- What? (adoption rate and return on investment)

- Why? (Upgrade technologies for benefits) and

- How? (partial or complete transformation of business processes by technology).

The above mapping and analysis leads us to our researchable question: What are the primary factors impacting adoption rate and return on investment in design thinking driven initiatives of emerging technologies that are intended for technology upgrade with benefits involving partial or complete transformation of business processes?

\section{LITERATURE REVIEW}

Emerging technologies impact employer and employees' jobs by significantly improving productivity and user experience by upgrading features and capabilities of enterprise systems. There is very limited amount of research work done on factors influencing adoption rate of newer technologies especially while using design thinking methodologies for ideation.

A wide literature search was conducted (using EBSCO) and google scholar to assess a list of significantly relevant theories and variables in this area, given that it was challenging to narrow down on the most relevant theory from the outset. Hence, to begin with I reviewed existing literature on technology adoption by multiple business functions and types around the world.

A research study has been conducted to understand the benefits and reasons for adoption of new technologies in agriculture by Taiwanese farmers (Shu Chun Chang, Ching-Horng Tsai, 2015) ${ }^{[3]}$. It was interesting to understand a human-centric field like Mortgage banking adopt technology for ensuring compliance with evolving rules and regulations (Rick Hill, Cindy Bojokles, 2012). In another survey of four CIOs from Vail resorts, Virgin America, Dannon company, Genentech (Stephanie Overby, 2008) ${ }^{[5]}$, secrets of early adopters are revealed.

CIOs summarize 7 tips for success with emerging tech and recipes for success. Adopting radical innovation techniques of design thinking, Professors from Tepper school of business and Carnegie Mellon university discuss about bridging theory and practice for commercialization and innovation (Arthur A. Boni, Tim Cunnigham, Jean Marie Sloat, 2018) ${ }^{[1] .}$

Known Limitation and Identification of Research Gaps:

While a lot of research cited above has been made in the areas of emerging technologies, adoption and design thinking initiatives etc., exact intersection of design thinking techniques with adoption of emerging technologies in IT-based business processes is yet to be conducted and published. There also is a possibility of bias when research studies are conducted by consulting firms, senior management versus the ones that actually involve the employees and business process executives impacted on the ground by these projects (Ives, B. and Olson, M.H, 1984) ${ }^{[2]}$

Keeping in mind this limitation, it becomes imperative to conduct extensive primary research both from the top-down angle involving design thinking consultants, senior executives as well as a bottom-up angle involving the business process executives working on the areas impacted by adoption of emerging technology. Also, additional factors both intrinsic and extrinsic to the company needs to be analyzed.

\section{THEORY/THEORIES}

\section{Activity Theory (Scaffolds of context)}

Activity theory framework describes structure, development and socio-cultural context of people's activities (Carolien Postma, Kristina Lauche, Pieter Jan Stapper, 2012) [6].

This framework adopts a holistic view on the activity involved in adoption of emerging technologies, people involved, objective of the people involved including the decision-makers, design thinking consultants as well as the business process executives impacted by technology intervention, actions and operations performed, tools and technologies used, how these technologies help them? rules, norms, procedures, group think etc.,

As per Engenstrom's model of activity system, two fundamental ideas viz., unity of consciousness and activity and social nature of the human mind are at the core of the activity theory. According to him, activity theory bridges the gap between the human mind and the world as well as between the individual and the social. Assessing Engenstrom's 5-concept Model of An Activity System:

The activity system is the basic unit of analysis of the activity theory. There are six components or factors associated with the activity system. Subject, object, mediating artifacts, rules, community and division of labor. There are five concepts associated with the activity system which are object orientedness, activity hierarchy, internalization and externalization, mediation and historicity and development. The importance of user involvement especially in validation and verification phase of such emerging technology adoption projects is also paramount to corroborate the efficacy of the initiative (Turban, 1990) ${ }^{[4] .}$

\section{ARIABLES OR FACTORS}

Independent/Predictor Variables (IV)

Object orientedness, hierarchy in activity, internalization and externalization, mediation, historicity and willing and active participation of domain experts are all the independent variables or predictor variables for determining the success of technology projects embracing emerging technologies.

Dependent/Criterion Variable (DV)

Rate of technology adoption with higher return on investment across private enterprises is the dependent variable or the criterion variable

Moderating Variable (MoV)

Employees trained and percentage productivity improved. These are chosen because most technology adoption initiatives are aimed at upgrading user experience and customer experience.

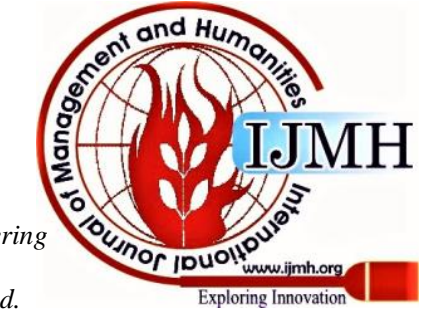


It is likely that employees with lesser training and processes with little scope of improving employee's experience (due to nature of added overheads) might be impacted the highest.

Mediating Variables (MeV)

Number of jobs restructured: This is chosen because, over a period time. Due to a new technology migration, certain executives in the company might get promoted based on the outcome while the actual users of the systems might be moved out or reskilled to other business services areas.

Hypothesis/Hypotheses (or research problem (s))

Theory and Concept

As identified in the theory section the key theory that we will be evaluating for this research is Activity theory based on social theory. Based on the five concepts of activity theory viz., object-orientedness, activity hierarchy, internalization and externalization, mediation and historicity and development and the six components which are subject, object, mediating artifacts, rules, community and division of labor, we can deduce the factors that could have an impact on the adoption rate and return on investment for emerging technology initiatives.

We also need to take into consideration the involvement of subject matter experts during design thinking phase of ideation for successful adoption (Turban, 1990) ${ }^{[4] .}$

\section{HYPOTHESES AND VARIABLES MAPPING:}

Using deductive approach on Activity theory, Turban's theory of user involvement and Engenstrom's model of activity system, following is the list of hypotheses across identified variables from the previous section. These factors are ordered based on these five concepts and six components.

Table- I: List of hypotheses - Variables and mapping

\begin{tabular}{|l|l|l|l|l|}
\hline \multicolumn{4}{|l}{ Activity theory based on social theory - Engenstrom's model of activity system } \\
\hline H(N) & Concept & Variable & Null hypothesis Ho & Alternate hypothesis HA \\
\hline H1 & $\begin{array}{l}\text { Object } \\
\text { orientedness }\end{array}$ & $\begin{array}{l}\text { Objective } \\
\text { (driven) }\end{array}$ & $\begin{array}{l}\text { Objective has a positive } \\
\text { impact on technology } \\
\text { adoption rate }\end{array}$ & $\begin{array}{l}\text { Objective does not have a positive } \\
\text { impact on technology adoption rate }\end{array}$ \\
\hline H2 & $\begin{array}{l}\text { Activity } \\
\text { (right person } \\
\text { for the right } \\
\text { job) }\end{array}$ & $\begin{array}{l}\text { Talent fitment has a } \\
\text { positive impact on } \\
\text { technology adoption rate }\end{array}$ & $\begin{array}{l}\text { Talent fitment does not have a } \\
\text { positive impact on technology } \\
\text { adoption rate }\end{array}$ \\
\hline H3 & $\begin{array}{l}\text { Externalization } \\
\text { Endization }\end{array}$ & $\begin{array}{l}\text { Stakeholder } \\
\text { buy-in }\end{array}$ & $\begin{array}{l}\text { Stakeholder buy-in has a } \\
\text { positive impact on } \\
\text { technology adoption rate }\end{array}$ & $\begin{array}{l}\text { Stakeholder buy-in does nove a } \\
\text { positive impact on technology } \\
\text { adoption rate }\end{array}$ \\
\hline H4 & Mediation & $\begin{array}{l}\text { Enabling } \\
\text { leadership } \\
\text { (activators) }\end{array}$ & $\begin{array}{l}\text { Enabling leadership has a } \\
\text { positive impact on } \\
\text { technology adoption rate }\end{array}$ & $\begin{array}{l}\text { Enabling leadership does not have a } \\
\text { positive impact on technology } \\
\text { adoption rate }\end{array}$ \\
\hline H5 & $\begin{array}{l}\text { Historicity and } \\
\text { development }\end{array}$ & $\begin{array}{l}\text { (proof of } \\
\text { success) }\end{array}$ & $\begin{array}{l}\text { Past success has a } \\
\text { positive impact on } \\
\text { technology adoption rate }\end{array}$ & $\begin{array}{l}\text { Past success does not have a positive } \\
\text { impact on technology adoption rate }\end{array}$ \\
\hline & $\begin{array}{l}\text { Psychological } \\
\text { (Esteem) }\end{array}$ & $\begin{array}{l}\text { User } \\
\text { involvement }\end{array}$ & $\begin{array}{l}\text { has a positive impact on } \\
\text { technology adoption rate }\end{array}$ & $\begin{array}{l}\text { User active involvement does not } \\
\text { have a positive impact on } \\
\text { technology adoption rate }\end{array}$ \\
\hline
\end{tabular}

\section{PLANNED DATA COLLECTION METHOD (S)}

Primary Data Collection and Pilot Using a Survey Questionnaire:

There needs to be high anonymity and external validity as the research problem needs to be applicable across industries that deploy emerging technology initiatives. Hence, we need to collect data from a large number of respondents at global scale. Considering all of the requirements above, the best primary data collection method for this research is a survey questionnaire.

Based on this, our survey questionnaire can be two-fold:

- A pilot testing on a small sub-set of population (of at least 32 respondents so that we avoid student t-distribution for more confidence levels) with don't know or no opinion wherever applicable,

- A roll out of the questionnaire to the population identified across industries. The questions will have to be comparative than absolute considering the nature of the variables. Hence, we will adopt the 'Five-point Likert' scale to frame the questions.

Secondary Data Collection
Once primary data is collected using survey questionnaire technique, we can then collect and analyze secondary data to corroborate and support our theories. In our research, we would need to collect the following information around the variables involved in our hypotheses to support a correlation between those and technology adoption rate and successful return on investment.

Objective Driven:

We can collect data from project charters of enterprise technology initiatives to assess if they were really objective driven and if they had set targets and goals which were measurable. This should be available from PMP (Project management plan) systems of the company.

Talent Fitment:

We can collect data around the key project executives from the HRM systems of the company to check if the right skill sets were deployed in executing such emerging technology projects. 
Stakeholder Buy-in:

We can collect this data from project charter gating criteria archives to see if all necessary stakeholder buy-in were successful across multiple functions in the company like process executives, senior leadership, procurement, IT, HR, Legal etc.,

Enabling Leadership:

We can collect data about the project sponsor from the executive summary of the projects available in PMP system archives of the company to see if there was significant drive top-down from leadership to sponsor and enable such projects on a dedicated basis

User Involvement:

We can collect the hours of training program and user input sessions on emerging technology initiatives to employees involved from company training reports and/or downloadable time sheets

\section{RESULT ANALYSIS:}

Based on hypothesis exercise, we are able to confirm activity theory, Turban theory and Engenstrom's model that the following factors have a significant impact:

Object driven, Talent fitment, Stakeholder buy-in, Enabling leadership, Past success and User involvement.

Based on an initial survey of 32 executives from organizations driving large scale adoption of RPA (Robotic Process Automation) in their respective organizations, we marked the variables that had more than $70 \%$ affirmative response. We found out that the following variables played an important role in enabling their decision to adopt such emerging technologies.

More than $90 \%$ of the respondents felt that there is a need for an analysis driven workshop fueled by techniques like design thinking to understand the requirements better. This not only helps them understand and empathize with the users better but also map out the initial scope, assumptions, dependencies and risks of adopting such technologies.

\begin{tabular}{|c|c|c|c|c|c|c|}
\hline $\begin{array}{c}\text { Is this } \\
\text { key? }\end{array}$ & $\begin{array}{c}\text { Object } \\
\text { driven }\end{array}$ & $\begin{array}{c}\text { Talent } \\
\text { Fitment }\end{array}$ & $\begin{array}{c}\text { Stakeholder } \\
\text { Buy-in }\end{array}$ & $\begin{array}{c}\text { L eadership } \\
\text { Support }\end{array}$ & $\begin{array}{c}\text { Past } \\
\text { success }\end{array}$ & $\begin{array}{c}\text { User } \\
\text { involvement }\end{array}$ \\
\hline $\begin{array}{c}>70 \% \\
\text { response }\end{array}$ & Yes & Yes & Yes & Yes & Yes & Yes \\
\hline
\end{tabular}

This further confirms the activity theory variables that we selected for the hypotheses. Further based on the voice of customer, we were able to confirm that the following input parameters for adopting the projects become clear when starting such initiatives with a design thinking like workshop

1. Scope of the project

2. Assumptions clearly outlined

3. Dependencies identified

4. Risks captured up front

\section{CONCLUSION AND RECOMMENDED NEXT STEPS:}

Based on hypothesis exercise, we can identify the factors influencing adoption of emerging technologies in large scale organizations. Based on these categories and sub-categories identified as a result of literature review and research analysis, there is scope for future study and correlation analysis. This can be done by conducting a research study in organizations through surveys, the result of which can be a source of primary data. Regression analysis can be conducted to identify key independent variables that contribute to overall adoption of technology innovation in organizations. This study can be coupled with analyzing financial statements to understand impact and benefits of such initiatives across organizations.

Interesting comparison can then be done to identify benefits of technology innovation across organizations.

The findings of this study can further be extended to design initiatives targeting specific key influential factors to maximize adoption of lateral innovation.

Further survey through a questionnaire distributed to employees as well as executives in organizations can help understand key factors influencing such adoption. This in juxtaposition with design thinking can provide useful insights into inhibitors as well as promoters of technology advancement in large organizations.

Hence, one can conclude that the improved adoption of emerged technologies in corporations should always begin with a design-thinking exercise for end-user buy in and empathizing with the customer pain points. Well defined objective, identifying the right people to drive such initiatives, top leadership support and active involvement of the actual users of the technology will play a significant role in improved adoption and long-term successes of such initiatives.

\section{REFERENCES}

1. Boni, A.A. (2018). Bridging Theory and Practice for Commercialization and Innovation - a Market-Centered Perspective for Cross- Industry Applications. Journal of Commercial Biotechnology, 24(1).

2. Ives, B. and Olson, M.H. (1984). User Involvement and MIS Success: A Review of Research. Management Science, 30(5), pp.586-603.

3. Chang, S.C. and Tsai, C.-H. (2015). The adoption of new technology by the farmers in Taiwan. Applied Economics, 47(36), pp.3817-3824.

4. Trippi, R.R. and Efraim Turban (1990). Investment management: decision support and expert systems. New York: Van Nostrand Reinhold.

5. Overby. S (2008). Early adopters. [online] CIO.com, pp.4-5. Available at: https://hbr.org/2000/05/cracking-thecode-of-change

6. Postma, C., Lauche, K. and Stappers, P. (2012). Social Theory as a Thinking Tool for Empathic Design. [online] Massachusetts institute of technology, pp.39-42. Available at: https://www.mitpressjournals.org/doi/pdfplus/10.1162/DESI_a_00122

\section{AUTHORS PROFILE}

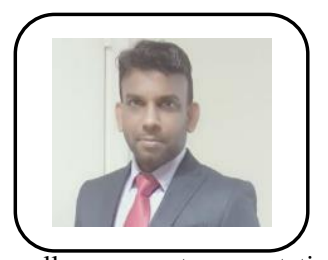

Nandakumar Kumar, is a doctoral candidate at S P Jain School of global management, Sydney, Australia and has an MBA in general management from The University of Iowa, USA. His current research includes application of lateral innovation tecnhiques in large corporations. He has published articles in several forums, international conferences as well as corporate presentations. He has over 15 years of progressive industry experience transforming business partner ecosystems through digital disruption and innovation. His areas of interest and expertise include A.I. and automation, Business process management, Block chain and IoT, Analytics and reporting, Lateral innovation techniques and Design Thinking. He has worked with a number of Fortune 50 Financial institutions, Large retailers, Automotive and Manufacturers in this space. He is certified Microsoft Professional (RDBMS), LEAN/Six Sigma, Automation anywhere, Pega BPM, Block Chain and is a Citizen Data Scientist. He has published several whitepapers, POVs and has delivered workshops and discussion forums for The Times group (Media house), Institute of Robotic Process Automation (IRPA), Business schools and Client in-house journals in topics around A.I, Design Thinking, Process excellence, Brand management, Consumer behavior etc. 